\title{
Identification of the Chemical Constituents of the Selected Fraction of the Dichloromethane Extract of Syzygium samarangense Stem Bark Using LC-ESI-MS and Evaluation Its Potential as Antifungal Agent
}

\author{
Tukiran*, Suyatno, and Frisca Nadya Safitri \\ Department of Chemistry, Faculty of Mathematics and Natural Sciences, Universitas Negeri Surabaya, Jl. Ketintang, Surabaya \\ 60231, Indonesia
}

\author{
*Corresponding author: \\ tel: $+62-85607012664$ \\ email: tukiran@unesa.ac.id \\ Received: April 13, 2020 \\ Accepted: February 8, 2021
}

DOI: $10.22146 /$ ijc.55366

\begin{abstract}
Several extracts of Syzygium species have been shown to inhibit the growth of some fungal microorganisms implicated in skin diseases, such as Candida albicans included S. samarangense. However, an antifungal test of C. albicans on this plant's stem bark had not been reported. This study aimed to identify chemical constituents of the selected fraction from dichloromethane extracts of the stem bark of S. samarangense and determine the antifungal activity of the selected fraction at various concentrations on $\mathrm{C}$. albicans. The identification of the chemical constituent of the selected fraction has been performed by the LC-ESI-MS technique. An antifungal test of the selected fraction was carried out using the disk diffusion method. The samples used included the selected fraction with 5 variations of concentration $(2.5 ; 2.0 ; 1.5 ; 1.0$; and $0.5 \%)$, positive control (ketoconazole 1\%), and negative control (DMSO). The results showed that the selected fraction has antifungal activity on $\mathrm{C}$. albicans. The results showed that the selected fraction contains four flavonoids: pinocembrin, uvangoletin, stercurensin, and aurentiacin. Due to antifungal activity on C. albicans, it has moderate activity at a concentration of $2.5 \%$, while concentrations of $2.0,1.5,1.0$, and $0.5 \%$ have weak activity.
\end{abstract}

Keywords: antifungal; C. albicans; flavonoids; LC-ESI-MS; S. samarangense

\section{- INTRODUCTION}

Infection can be caused by various microorganisms such as bacteria, viruses, and fungi. Fungal infections affect the skin, hair, or nails, and tend to thrive in the heat and humidity of tropical countries [1], belonging to Indonesia. As known that Indonesia is a country with high humidity which induces easy fungus growth. One of the fungi that can lead to skin infections is Candida albicans. C. albicans is an opportunistic human fungal pathogen that causes candidiasis. As reported that $C$. albicans has been prominent among the fungal pathogens [2].

Diseases caused by fungal infections of $C$. albicans are usually treated with antibiotics such as amphotericin, nystatin, ketoconazole, and griseofulvin. However, these antibiotics often lead to serious side effects, resistance, complicated rules of use, and the need for doctor supervision. In this regard, it is necessary to look for natural antifungal agents that are more effective and inexpensive derived from plants, for example, Syzygium plants (Myrtaceae), such as leaves of S. polyanthum [3] and S. aromaticum cloves [4-5].

While other Syzygium plants that similar studies have carried out are $S$. malaccense, i.e., the methanolic extract of $S$. malaccence leaves showing effective antimicrobial activity against C. albicans [6], essential oils of $S$. aromaticum for their anti-biofilm activity against strong biofilm-forming strains of C. albicans [7], hydroalcoholic extracts/fractions of $S$. cumini upon fungal growth of C. albicans [8], etc. However, antifungal tests on C. albicans from S. samarangense stem bark have never been reported till now.

In this antifungal test, the disk diffusion method was chosen to be used because their observations and measurements can be made visually and can detect inner colonies, which may indicate subpopulations that are more resistant and easier and faster in their work. The 
antifungal test that had ever been applied to Syzygium plants is S. polyanthum. Using the disk diffusion method, the ethanolic extract of $S$. polyanthum leaves with various concentrations $(0.5 ; 1.0 ; 1.5 ; 2.0$; and $2.5 \%)$, the results at a concentration of $1.0 \%$ the ethanolic extract showed a minimum inhibitory zone against $C$. albicans [9]. It is predicted that the antifungal activity of an extract of plants was influenced by the presence of secondary metabolite compounds such as alkaloids, phenols, flavonoids, saponins, and terpenoids [10-14].

\section{- EXPERIMENTAL SECTION}

\section{Material and Methods}

Materials used include: powdered S. samarangense stem bark, dichloromethane, $n$-hexane, filter paper, TLC plate, TLC sprayer or viscous agent used saturated solution, stationary phase for vacuum liquid chromatography (VLC) using Merck silica gel 60, stationary phase for gravitational column chromatography (GCC) using Merck silica gel 60, silica gel 60 F-254 for TLC plate, and suitable eluents. The solvents used in the chromatographic techniques included $n$-hexane and dichloromethane (Grade AR), and silica gel purchased from Merck (Germany). Materials (chemicals) for the antifungal test used are Sabouraud Dextrose Broth (SDB) liquid media, Potato Dextrose Agar (PDA) solid media, ketoconazole solution, distilled water, petri dish, filter papers, and C. albicans colonies. The stem bark of S. samarangense (c.a. $15 \mathrm{~kg}$ ) was collected from a local area in Kediri, East Java, Indonesia, in October 2018. The plant's identification was performed by the staff of Herbarium-LIPI, Purwodadi, East Java, Indonesia. A voucher sample is kept in the Herbarium of LIPI with Identification No. 1498/IPH.06/HM/X/2018, October 18, 2018.

\section{Equipment and Instruments}

The equipment used to do extraction and fractionation were filter paper, Buchner funnel, Hirsch funnel, Erlenmeyer flask, pipette, spatula, measuring flask, vials, containers, separating funnel, and vacuum rotary evaporator type BUCHI Rotavapor R-215. Whereas chromatographic techniques used to fractionate the chemical constituents from dichloromethane extracts, including Vacuum Liquid Chromatography (VLC) (silica gel 60, 0.200-0.500 mm), Gravitational Column Chromatography (GCC) (silica gel 60, 0.063$0.200 \mathrm{~mm}$ or $70-230$ mesh ASTM), and TLC analysis were carried out on silica gel 60 F254 chromaplates with the developing solvent systems. Checking the homogeneity of the fractions was made by TLC on Kieselgel 60 F254 pre-coated sheets (Merck), and the spots were detected by exposure to UV-lamp at 254 or $366 \mathrm{~nm}$.

Equipment used to evaluate antifungal property included refrigerators, incubator, crucible porcelain, desiccator, Biological Safety Cabinet (BSC), Laminar Air Flow (LAF), autoclave, glassware, pipette Pasteur glass, ose needle, microscope, tip, and micropipette, etc. An instrument needed to identify the phytoconstituents for the selected fraction of the dichloromethane extract of $S$. samarangense was ion-trap mass spectrometry in negative ion modes (Shimadzu LCMS-8040 LC/MS analysis).

\section{Procedure}

\section{Extraction and separation}

The fresh stem bark of $S$. samarangense (c.a. $15 \mathrm{~kg}$ ) was washed under tap water and dried under sunlight for one week. It was then dried in an oven at a reduced temperature (not more than $50{ }^{\circ} \mathrm{C}$ ) to make it suitable for grinding purposes. It was then ground to a fine powder using an electric grinder to obtain $9.5 \mathrm{~kg}$ and transferred to an airtight container. The dried and powdered stem bark $(9.5 \mathrm{~kg})$ of $S$. samarangense was macerated with dichloromethane (c.a. $25 \mathrm{~L}$ ) at room temperature. The container with its content was sealed by foil and kept for a period of $24 \mathrm{~h}$ accompanying occasional shaking and stirring, and carried out three times. The whole mixture was then filtered using the Buchner funnel, and the filtrate was concentrated at $50{ }^{\circ} \mathrm{C}$ with a vacuum rotary evaporator. The concentrated extract obtained is termed as a crude extract $(60.79 \mathrm{~g})$ of a thick light brown, and this extract will be used to be materials in this study.

As much as $12 \mathrm{~g}$ of dichloromethane extract was separated using VLC with eluents (n-hexane- 
dichloromethane for increasing the polarity) to yield 22 fractions. This way is carried out three times to increase the mass of each fraction. Based on TLC analysis, all fractions that gave the same value of $R f$ could be combined and grouped into seven significant fractions, namely fraction A (1-4), B (5-6), C (7-9), D (10-12), E (13-14), F (16-18), G (19-22). Furthermore, separation is focused on fraction B and separated using GCC with eluents ( $n$ hexane-dichloromethane $=5: 5)$ to yield 35 fractions and can be grouped into five fractions, namely fractions A (13), B (4-13), C (14-19), D (20-30), and E (31-35). When looking at the chromatogram profile resulted, it seemed that fraction B contains quite simple spots. The fraction B then was identified its chemical components using the LC-MS method and can be elaborated as follows.

Liquid Chromatography-Mass Spectroscopy (LCMS) analysis. Analysis for identifying chemical components was performed using an LC system (Shimadzu LCMS - 8040 LC/MS). $1 \mu \mathrm{L}$ of a sample was injected into the LC instrument equipped with the column of Shim Pack FC-ODS $(2 \mathrm{~mm} \times 150 \mathrm{~mm}, 3 \mu \mathrm{m}$ particle sizes) and column temperature $35^{\circ} \mathrm{C}$. The LCMS separations are carried out with isocratic elution with dichloromethane as a mobile phase at a flow rate of $0.5 \mathrm{~mL} / \mathrm{min}$. The parameters for analysis were carried out using a negative ion mode as follows: source temperature $100^{\circ} \mathrm{C}$, sampling cone voltage $23 \mathrm{eV}$, capillary voltage 3.0 $\mathrm{kV}$, desolvation temperature $350^{\circ} \mathrm{C}$, and desolvation gas flow $60 \mathrm{~mL} / \mathrm{h}$. Mass spectra were detected in the ESI negative ion mode between $\mathrm{m} / z 10-1000$ with scanning duration ( $0.6 \mathrm{sec} / \mathrm{scan})$ and running time $(25 \mathrm{~min})$.

The chemical components of fraction B (4-13) derived from the dichloromethane extract of $S$. samarangense were further analyzed using the LC-MS method, resulting in a chromatogram profile as shown in Fig. 1. It can be seen that the profile showed four peaks with their respective abundances (composition \%), and Table 1 listed all the compounds identified with their chromatographic: retention time and mass spectral data with a similarity index of $92 \%$.

\section{Antifungal test by the disc diffusion method}

As the first step before doing an antifungal test, it was necessary to sterilize all the tools that will be used. The whole tools were washed clean, dried, and then wrapped using paper, then sterilized in an autoclave at $121^{\circ} \mathrm{C}$ for c.a. $15 \mathrm{~min}$. Next was preparing culture media specific for C. albicans. In this case, it was used PDA (Potato Dextrose Agar) solid media and SDB (Sabouraud Dextrose Broth) liquid media. The preparation of PDA solid media can be explained as follows. As much as $250 \mathrm{~mL}$ of distilled water was prepared to be heated to boiling. When boiling, $9.75 \mathrm{~g}$ of PDA powder was put into it and stirred continuously until it dissolves completely. The next step was preparing the SDB liquid media, which can be explained as follows. As much as $100 \mathrm{~mL}$ of distilled water was prepared to be heated to boiling. When boiling, $3 \mathrm{~g}$ of SDB

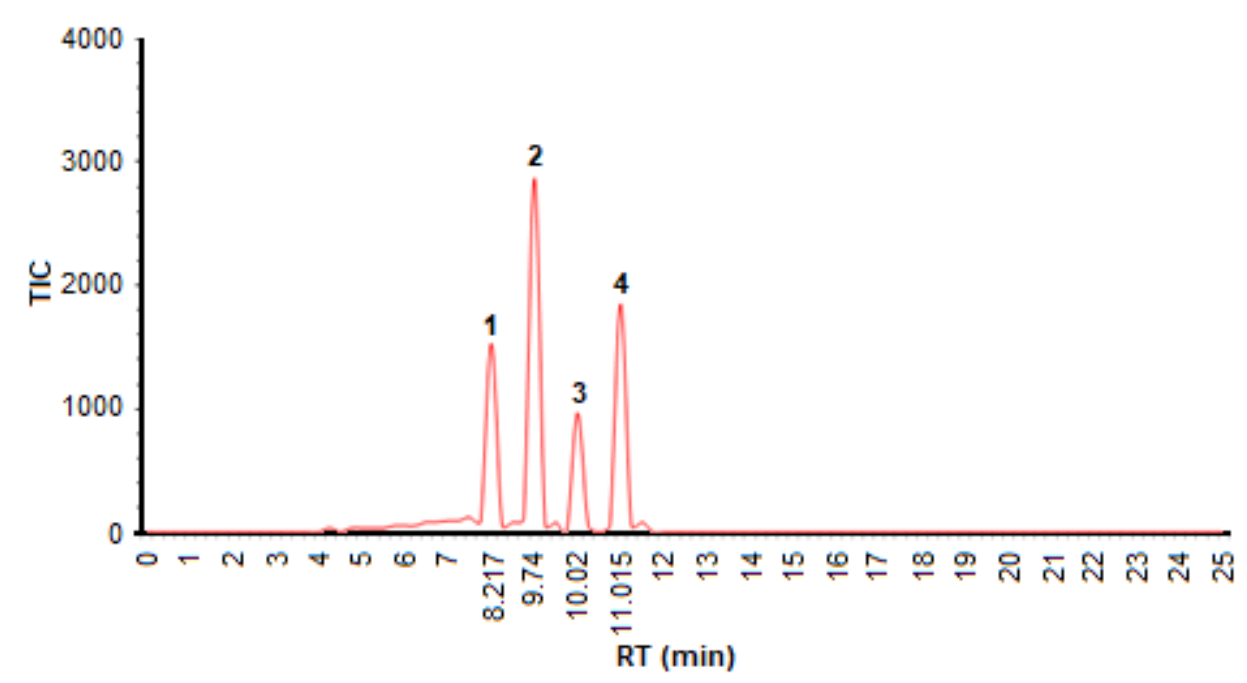

Fig 1. The Chromatogram profile of LCMS for fraction B (4-13) 
Table 1. Tentative identification of chemical constituents of fraction B derived from the dichloromethane extract of $S$. samarangense stem bark by using LC-MS technique based on the chromatogram database (library) resume report

\begin{tabular}{|c|c|c|c|c|}
\hline \multirow{2}{*}{$\begin{array}{c}\text { Compound } \\
\text { No }\end{array}$} & \multirow{2}{*}{$\mathrm{Rt}(\min )$} & \multirow{2}{*}{$\begin{array}{c}\text { Composition } \\
(\%)\end{array}$} & \multicolumn{2}{|l|}{ Compound result } \\
\hline & & & Analysis & Identified compounds \\
\hline 1 & 8.217 & 21.2 & $\begin{array}{l}\text { Chemical formula: } \mathrm{C}_{15} \mathrm{H}_{12} \mathrm{O}_{4} \\
\text { Exact mass: } 256.0736 \\
\text { Molecular weight: } 256.2570 \\
\mathrm{~m} / \mathrm{z}: 256.0736(100.0 \%), 257.0769(16.2 \%) \text {, } \\
\text { and } 258.0803(1.2 \%)\end{array}$ & Pinocembrin \\
\hline 2 & 9.740 & 39.8 & $\begin{array}{l}\text { Chemical formula: } \mathrm{C}_{16} \mathrm{H}_{16} \mathrm{O}_{4} \\
\text { Exact mass: } 272.1049 \\
\text { Molecular weight: } 272.3000 \\
\mathrm{~m} / \mathrm{z}: 272.1049(100.0 \%), 273.1082(17.3 \%) \text {, } \\
\text { and } 274.1116(1.4 \%)\end{array}$ & Uvangoletin \\
\hline 3 & 10.020 & 13.4 & $\begin{array}{l}\text { Chemical formula: } \mathrm{C}_{17} \mathrm{H}_{16} \mathrm{O}_{4} \\
\text { Exact mass: } 284.1049 \\
\text { Molecular weight: } 284.3110 \\
\mathrm{~m} / \mathrm{z}: 284.1049(100.0 \%), 285.1082(18.4 \%) \text {, } \\
\text { and } 286.1116(1.6 \%)\end{array}$ & Stercurensin \\
\hline 4 & 11.015 & 25.6 & $\begin{array}{l}\text { Chemical formula: } \mathrm{C}_{18} \mathrm{H}_{18} \mathrm{O}_{4} \\
\text { Exact mass: } 298.1205 \\
\text { Molecular weight: } 298.3380 \\
\text { m/z: } 298.1205(100.0 \%), 299.1239(19.5 \%) \text {, } \\
\text { and } 300.1272(1.8 \%)\end{array}$ & Aurentiacin \\
\hline
\end{tabular}

powder was put into it and stirred continuously until it dissolves completely. Both media were stored in sterilized bottles, then sterilized using an autoclave at $121{ }^{\circ} \mathrm{C}$ for \pm 15 min. PDA solid media that has been sterilized was then allowed to stand at room temperature until the temperature is $\pm 40^{\circ} \mathrm{C}$ and then poured into the petri dish as much as $12-15 \mathrm{~mL}$ and allowed to solidify. After solidifying, the PDA media is ready to use.

The next step was making C. albicans fungi stock which can be explained as follows. Fungi stock can be prepared by inoculating and scraping one needle of ose $C$. albicans culture in the PDA media, then incubated for 24$48 \mathrm{~h}$ at $37^{\circ} \mathrm{C}$ in an incubator. Rejuvenation of C. albicans culture was carried out by preparing $50 \mathrm{~mL}$ of sterilized SDB liquid media, then supplementing with 1 ose of $C$. albicans taken from the media aseptically and vortex to make it homogeneous. It was then incubated at $37^{\circ} \mathrm{C}$ for $24 \mathrm{~h}$.

Testing sample activity against $C$. albicans was carried out using the disk diffusion method, which can be mentioned. As much as $1 \mathrm{~mL}$ of sample (fraction B) from dichloromethane extract of $S$. samarangense stem bark at the various concentration $(0.5 ; 1.0 ; 1.5 ; 2.0$; and $2.5 \%)$, positive control (ketoconazole $1 \%$ solution), and negative control (DMSO) prepared was put into a sterilized petri dish, then put $6 \mathrm{~mm}$ diameter disk paper on it and saturated for $15 \mathrm{~min}$. Furthermore, the solidified PDA solid media was prepared to be added with a suspension of C. albicans fungi stock of $100 \mu \mathrm{L}$ taken from SDB liquid media with a cell density of $10^{-7}$. It was spread as evenly as possible on top of the media to be affixed with saturated disc paper using an L-pipe. Petri dishes were incubated at $37^{\circ} \mathrm{C}$ for $24 \mathrm{~h}$. The inhibition zone was marked by a clear area (zone) around the disc on a solid media surface, then measured using a caliper in millimeters ( $\mathrm{mm})$ [15].

\section{Data analysis}

Data from the antifungal test results with the disc diffusion method above were analyzed statistically using the SPSS program version 16.0 for the window, 
including normality test (Kolmogorov-Smirnov), homogeneity (Levene's test), and continued with the nonparametric Kruskal-Wallis test.

\section{- RESULTS AND DISCUSSION}

\section{LC-ESI-MS Analysis of the Selected Fraction of Dichloromethane Extract from $S$. samarangense Stem Bark}

Liquid chromatography coupled with mass spectrometry (LC/MS) is a powerful and new technique for identifying complex botanical extracts [16-17]. It provides information for structural elucidation of the components of these extracts. Therefore, in the present work, the selected fraction of dichloromethane extract of S. samarangense was submitted to LC connected with MS spectrometry in negative ion mode. The identification of the chemical components of this fraction was carried out through their retention times, composition (\%), and molecular weights (MW), as shown in Fig. 1). By comparing these data with the standards (database (library)), it can be identified the components as shown in Table 1.

Fraction B then was identified its chemical components using LC-ESI-MS, and the result is known to contain four flavonoids, namely pinocembrin (1), uvangoletin (2), stercurensin (3), and aurentiacin (4), as shown in Fig. 2.

The four compounds identified above can be classified into two groups of flavonoids, namely 1) flavanone derivative (compound 1) and 2) chalcone derivative (compounds $\mathbf{2}, \mathbf{3}$, and $\mathbf{4}$ ). These compounds in the same Syzygium plants and others can be explained in detail as follows.

\section{Flavanone derivative}

Pinocembrin (1), 5,7-dihydroxyflavanone, is one of the primary flavonoids isolated from various plants [18]. Compound 1 and two phenolic acids: gallic acid and ellagic acid, had been found from the methanolic extracts of the pulp and seeds of the fruits of $S$. samarangense [19]. The compound had also been isolated in the leaf extract of $S$. samarangense [20] and together with 8-methylpinocembrin had been found from S. samarangense [21]. Compound 1 along with gallic acid, 3,4,3'-tri-O-methylellagic acid, and 3,3'-di$O$-methylellagic acid had also been isolated from the methanolic extract of $S$. polycephalum stem bark [22].

\section{Chalcone derivatives}

Chalcones are a subgroup of flavonoids. They are characterized by the absence of 'ring $\mathrm{C}^{\prime}$ of the basic flavonoid skeleton structure, as shown in Fig. 3. Compounds such as uvangoletin (2), stercurensin (3), and aurentiacin (4) can be grouped to be chalcone derivatives because they have the basic skeleton of chalcones.

Compound 2, for the first time, along with angoletin (dihydrochalcones) and the known $C$ benzyldihydro chalcones, uvaretin, and isouvaretin, had<smiles>O=C1C[C@H](c2ccccc2)Oc2cc(O)cc(O)c21</smiles><smiles>COc1cc(O)cc(O)c1C(=O)CCc1ccccc1</smiles><smiles>COc1cc(O)c(C)c(O)c1C(=O)/C=C/c1ccccc1</smiles>

3<smiles>COc1cc(OC)c(C(=O)/C=C/c2ccccc2)c(O)c1C</smiles>

4

Fig 2. The molecular structure of identified compounds 
been isolated from the roots of Uvaria angolensis (Annonaceae) [23]. Compound 2, a 2',4'-dihydroxy-6'methoxydihydro chalcone, had also been found the roots of Uvaria acuminata (Annonaceae) [24]. In Myrtaceous plants, compound $\mathbf{2}$ had been isolated from the leaves of S. samarangense (Myrtaceae) [25].

Compound 3 (called as 2',4'-dihydroxy-6'-methoxy3'-methylchalcone, stercurensin) along with 2',4'dihydroxy-6'-methoxy-3',5'-dimethylchalcone, and 2',4'dihydroxy-6'-methoxychalcone (cardamonin) was isolated from methanolic extracts of the pulp and seeds of the fruits of S. samarangense [19,26]. Compound 3, an active compound isolated from the leaves of $S$. samarangense, was known to have anti-inflammatory activity [27]. Besides, compound 3 together with 2',4'-dihydroxy-6'methoxy-3'-methyldihydrochalcone, $\quad 2^{\prime}$-hydroxy-4', $6^{\prime}$ dimethoxy-3'-methylchalcone (aurentiacin, 4), 2',4'dihydroxy-6'-methoxy-3',5'-dimethylchalcone, and 7hydroxy-5-methoxy-6,8-dimethylflavanone, had been isolated from the leaves of $S$. samarangense [28].

Compound 4 and flavokawin B were isolated from the frond exudate of Pityrogramma triangularis var. pallida [29]. Besides, the compound 4, C-methylated chalcones, and myrigalon- $\mathrm{D}$ are the major constituents in leaf glands of Myrica pensylvanica (Myrtaceae) [30].

The dichloromethane extract of the leaves of $S$. samarangense afforded compounds 3 and $\mathbf{4}$ along with 2', 4'dihydroxy-6'-methoxy-3',5'-dimethyl-chalcone, squalene, betulin, lupeol, sitosterol, and a mixture of cycloartenyl stearate, lupenyl stearate, $\beta$-sitosteryl stearate, and 24methylenecycloartenyl stearate [31]. Also, compound 3 had been isolated from the leaf extract of $S$. campanulatum [32].

Testing of antifungal activity of samples on $C$. albicans was performed three times, and the results of measurement of inhibition zones diameters of the fraction B from dichloromethane extract of $S$. samarangense stem bark can be presented in Table 2 . The inhibition zone diameter response $(\mathrm{mm})$ of samples toward the growth of C. albicans can be classified as very strong $(20-30 \mathrm{~mm})$, strong $(10-20 \mathrm{~mm})$, moderate (5$10 \mathrm{~mm})$, and weak $(<5 \mathrm{~mm})$. The inhibition zone's small diameter indicates a low antifungal activity, while the inhibition zone's large diameter indicates a higher antifungal activity [33].

As shown in Table 2, it seemed that fraction B has an antifungal activity to inhibit the growth of C. albicans. The lowest inhibition zone diameter is indicated at the concentration of fraction B of $0.5 \%$, an average diameter of $0.50 \mathrm{~mm}$. Simultaneously, the highest inhibition zone is shown at the concentration of fraction B of $2.5 \%$, which is an average diameter of $5.00 \mathrm{~mm}$. Next, on control positive using ketoconazole $1 \%$ formed a larger inhibition zone compared to the fraction $\mathrm{B}$, an average diameter of $12.50 \mathrm{~mm}$.

A test using the One way ANOVA through the SPSS program has been applied to know the effect of<smiles>O=C(/C=C/c1ccccc1)c1ccccc1</smiles>

Fig 3. The basic skeleton of chalcone

Table 2. Results of measurement of inhibition zone diameters of several samples

\begin{tabular}{|c|c|c|c|c|c|}
\hline \multirow{2}{*}{$\begin{array}{c}\text { Concentration of samples } \\
(\%)\end{array}$} & \multicolumn{3}{|c|}{ The diameter of a clear zone $(\mathrm{mm})$} & \multirow{2}{*}{$\begin{array}{l}\text { Total } \\
(\mathrm{mm})\end{array}$} & \multirow{2}{*}{$\begin{array}{l}\text { Average } \\
(\mathrm{mm})\end{array}$} \\
\hline & I & II & III & & \\
\hline 2.5 & 5.0 & 5.0 & 5.0 & 15.00 & 5.00 \\
\hline 2.0 & 4.0 & 3.0 & 4.0 & 11.00 & 3.66 \\
\hline 1.5 & 3.0 & 2.0 & 2.0 & 7.00 & 2.33 \\
\hline 1.0 & 1.0 & 1.5 & 1.5 & 4.00 & 1.33 \\
\hline 0.5 & 0.5 & 0.5 & 0.5 & 1.50 & 0.50 \\
\hline Positive control & 12.50 & 12.50 & 12.50 & 37.50 & 12.50 \\
\hline Negative control & 0 & 0 & 0 & 0 & 0 \\
\hline Total & & & & 76 & 24.99 \\
\hline
\end{tabular}


fraction B inhibition toward C. albicans. It was obtained that the data resulted are not homogeneous. Therefore, the test was continued using non-parametric methods. The normality test was carried out using the One-sample Kolmogorov-Smirnov test, and the results can be presented in Table 3.

As presented in Table 3, the normality test obtained showed $p=0.414$ and $p=0.917$. As known that data normally distributed is to have $p>0.05$. Because of the value of $p>0.05$, the data in this study were stated to be normally distributed. The next is to do a homogeneity test using Levene's test, and the sig results obtained are 0.000 . It meant that the data is not homogeneous, so it is necessary to use a non-parametric test that is the Kruskal Wallis test.

The Kruskal Wallis test is a non-parametric test aiming to determine the presence or absence of statistically significant differences between two or more groups of independent variables on the dependent variable with numerical data (interval/ratio scale) and ordinal scale. The test is identical to the One Way ANOVA Test in a parametric test, so the test is an alternative if it does not meet the One Way ANOVA test requirements. The results of the Kruskal Wallis test of data can be shown in Table 4 .

In Table 4, it seems that the significance value is 0.003. If the significance value is less than 0.05 , so there is a significant influence. It means that fraction $B$ influences inhibiting the growth of fungi C. albicans.

Flavonoids are ubiquitous in photosynthesizing cells and are commonly found in fruit, vegetables, nuts, seeds, stems, flowers, tea, wine, propolis, and honey. Many compounds that have isolated and identified their structures possess antifungal activity, including flavonoids [34]. It was shown that the anti-pathogenic effect of flavonoids depends on their structure. It was suggested that the highest antifungal activity is demonstrated by unsubstituted flavones and unsubstituted flavanones (included pinocembrin, 1). Hydroxyl and methyl groups in these compounds reduce their antifungal properties, though in some cases, methylated flavonoids reveal a higher antifungal effect [35]. In general, flavonoids' mechanism of action in inhibiting fungal growth is by
Table 3. The results of normality test using One-sample Kolmogorov-Smirnov Test

\begin{tabular}{llcl}
\hline & & $\begin{array}{c}\text { Diameters } \\
(\mathrm{mm})\end{array}$ & Treatments \\
\hline $\mathrm{N}$ & 21 & 21 \\
Normal & Mean & 3.7619 & 4.0000 \\
Parameters $^{\mathrm{a}}$ & Std. Deviation & 4.07314 & 2.04939 \\
Most Extreme & Absolute & 0.193 & 0.121 \\
Differences & Positive & 0.193 & 0.121 \\
& Negative & -0.178 & -0.121 \\
Kolmogorov-Smirnov Z & 0.885 & 0.555 \\
Asymp. Sig. (2-tailed) & 0.414 & 0.917 \\
\hline
\end{tabular}

Test distribution is Normal

Table 4. The results of the Kruskal Wallis test of data

\begin{tabular}{ll}
\multicolumn{2}{c}{ Test Statistics $^{\mathrm{a}}$} \\
\hline Diameter $(\mathrm{mm})$ \\
\hline Chi-Square & 19.741 \\
Df & 6 \\
Asymp. Sig & 0.003 \\
\hline${ }^{\mathrm{a}}$ Grouping variable: Treatment Concentration
\end{tabular}

disrupting fungal cell membrane permeability. Hydroxyl groups presented in flavonoids cause changes in organic components and transport of nutrients, eventually leading to toxic effects on fungi [36].

\section{- CONCLUSION}

It had been identified by using an LC-ESI-MS technique several compounds from the selected fraction of the dichloromethane extract of $S$. samarangense stem bark, namely pinocembrin, uvangoletin, stercurensin, and aurentiacin. The chosen fraction has moderate activity at a concentration of $2.5 \%$, while concentrations of $2.0,1.5,1.0$, and $0.5 \%$ have weak activity. The higher the concentration of the fraction tested, the greater the inhibition zone diameter formed.

\section{- ACKNOWLEDGMENTS}

We thank the Directorate of Research and Innovation Empowerment, the Ministry of Research, Technology, and the National Research and Innovation Agency to support our project in the National Competitive Fundamental Research Scheme-2020. The 
authors also extend thanks to M. Ariesandy PT. Djarum Kudus Malang, East Java, Indonesia for help in LC-ESIMS measurements.

\section{- AUTHOR CONTRIBUTIONS}

All authors conducted the experiment, Frisca Nadya Safitri sent the sample to PT. Djarum Kudus Malang, Indonesia, for measuring LC-ESI-MS, and all authors wrote and revised the manuscript. All authors agreed to the final version of this manuscript.

\section{- REFERENCES}

[1] Charles, A.J., 2009, Superficial cutaneous fungal infections in tropical countries, Dermatol. Ther., 22 (6), 550-559.

[2] Kabir, M.A., Hussain, M.A., and Ahmad, Z., 2012, Candida albicans: A model organism for studying fungal pathogens, Int. Scholarly Res. Not., 2012, 538694.

[3] Kusuma, S.A.F., Purnamasari, E., and Herawati, I.E., 2019, Syzygium polyanthum (Wight) Walp. leaves extract as the antifungal agent for oral candidiasis, Drug Invent. Today, 12 (7), 1339-1342.

[4] Yassin, M.T., Mostafa, A.A.F., and Al-Askar, A.A., 2020, In vitro anticandidal potency of Syzygium aromaticum (clove) extracts against vaginal candidiasis, BMC Complementary Med. Ther., 20 (1), 25.

[5] Mansourian, A., Boojarpour, N., Ashnagar, S., Beitollahi, J.M., and Shamshiri, A.R., 2014, The comparative study of antifungal activity of Syzygium aromaticum, Punica granatum and nystatin on Candida albicans; An in vitro study, J. Mycol. Med., 24 (4), e163-e168.

[6] Purushothaman, A., Sudhir, A.S., Joby, G., Aravind, R., and Varghese, A., 2015, A study on antimicrobial and anthelmintic activity of methanolic leaf extracts of Syzygium malaccense (L.) Merr. \& Perry, J. Chem. Pharm. Res., 7 (4), 838-841.

[7] Khan, M.S.A., and Ahmad, I., 2012, Biofilm inhibition by Cymbopogon citratus and Syzygium aromaticum essential oils in the strains of Candida albicans, J. Ethnopharmacol., 140 (2), 416-423.
[8] Pereira, J.V., Freires, I.A., Castilho, A.R., da Cunha, M.G., Alves, H.S., and Rosalen, P.L., 2016, Antifungal potential of Sideroxylon obtusifolium and Syzygium cumini and their mode of action against Candida albicans, Pharm. Biol., 54 (10), 2312-2319.

[9] Höfling, J.F., Anibal, P.C., Obando-Pereda, G.A., Peixoto, I.A.T., Furletti, V.F., Foglio, M.A., and Gonçalves, R.B., 2010, Antimicrobial potential of some plant extracts against Candida species, Braz. J. Biol., 70 (4), 1065-1068.

[10] Guevara-Lora, I., Bras, G., Karkowska-Kuleta, J., González-González, M., Ceballos, K., Sidlo, W., and Rapala-Kozik, M., 2020, Plant-derived substances in the fight against infections caused by Candida species, Int. J. Mol. Sci., 21 (17), 6131.

[11] Yusoff, S.F., Haron, F.F., Tengku Muda Mohamed, M., Asib, N., Sakimin, S.Z., Abu Kassim, F., and Ismail, S.I., 2020, Antifungal activity and phytochemical screening of Vernonia amygdalina extract against Botrytis cinerea causing gray mold disease on tomato fruits, Biology, 9 (9), 286.

[12] Sakander, H., Akhilesh, B., and Koteshwara, A.R., 2015, Evaluation of antifungal potential of selected medicinal plants against human pathogenic fungi, Int. J. Green Pharm., 9 (2), 110-117.

[13] Ribera, A.E., and Zuñiga, G., 2012, Induced plant secondary metabolites for phytopatogenic fungi control: A review, J. Soil Sci. Plant Nutr., 12 (4), 893-911.

[14] Shakhatreh, M.A.K., Al-Smadi, M.L., Khabour, O.F., Shuaibu, F.A., Hussein, E.I., and Alzoubi, K.H., 2016, Study of the antibacterial and antifungal activities of synthetic benzyl bromides, ketones, and corresponding chalcone derivatives, Drug Des., Dev. Ther., 10, 3653-3660.

[15] Baharuddin, N.S., Abdullah, H., and Wan Abdul Wahab, W.N.A., 2015, Anti-Candida activity of Quercus infectoria gall extracts against Candida species, J. Pharm. BioAllied Sci., 7 (1), 15-20.

[16] Septaningsih, D.A., Darusman, L.K., Afendi, F.M., and Heryanto, R., 2018, Liquid chromatography mass spectrometry (LC-MS) fingerprint combined 
with chemometrics for identification of metabolites content and biological activities of Curcuma aeruginosa, Indones. J. Chem., 18 (1), 43-52.

[17] Zhang, A., Wan, L., Wu, C., Fang, Y., Han, G., Li, H., Zhang, Z., and Wang, H., 2013, Simultaneous determination of 14 phenolic compounds in Grape canes by HPLC-DAD-UV using wavelength switching detection, Molecules, 18 (11), 14241-14257.

[18] Rasul, A., Millimouno, F.M., Eltayb, W.A., Ali, M., Li, J., and Li, X., 2013, Pinocembrin: A novel natural compound with versatile pharmacological and biological activities, Biomed Res. Int., 2013, 379850.

[19] Aung, E.E., Kristanti, A.N., Aminah, N.S., Takaya, Y., and Ramadhan, R., 2020, Plant description, phytochemical constituents and bioactivities of Syzygium genus: A review, Open Chem., 18 (1), 12561281.

[20] Peter, T., Padmavathi, D., Sajini, R.J., and Sarala, A., 2011, Syzygium samarangense: A Review on morphology, phytochemistry and pharmacological aspects, Asian J. Biochem. Pharm. Res., 1 (4), 155-163.

[21] Majumder, R., Hasnat, N.E., Zaman, M.A.U., and Alam, M.B., 2014, In vivo evaluation of the pharmacological activities of Syzygium samarangense (Blume) Merr. \& L.M. Perry, Adv. Biol. Res., 8 (3), 107-115.

[22] Tukiran, Wardana, A.P., Hidajati, N., and Shimizu, K., 2019, Chemical components and antioxidant activities of methanol extract of Syzygium polycephalum Miq. stem bark (Myrtaceae), Indian J. Nat. Prod. Resour., 10 (2), 127-136.

[23] Hufford, C.D., and Oguntimein, B.O., 1980, Dihydrochalcones of Uvaria angolensis, Phytochemistry, 19 (9), 2036-2038.

[24] Ascherio, A., and Munger, K.L., 2010, Epstein-Barr virus infection and multiple sclerosis: A review, $J$. Neuroimmune Pharmacol., 5 (3), 271-277.

[25] Debnath, T., Chakraverty, R., and Chakraborty, P., 2019, Flavonoids from leaves of Syzygium samarangense and its pharmacological potential: Some recent insights, Pharmawave, 12, 15-19.

[26] Mukaromah, A.S., 2020, Wax Apple (Syzygium samarangense (Blume) Merr. \& L.M. Perry): A comprehensive review in phytochemical and physiological perspectives, Al-Hayat J. Biol. Appl. Biol., 3 (1), 40-58.

[27] Kim, Y.J., Kim, H.C., Ko, H., Amor, E.C., Lee, J.W., and Yang, H.O., 2011, Stercurensin inhibits nuclear factor- $\mathrm{kB}$-dependent inflammatory signals through attenuation of TAK1-TAB1 complex formation, $J$. Cell. Biochem., 112 (2), 548-558.

[28] Amor, E.C., Villaseñor, I.M., Nawaz, S.A., Hussain, M.S., and Choudhary, M.I., 2005, A dihydrochalcone from Syzygium samarangense with anticholinesterase activity, Philipp. J. Sci., 134 (2), 105-111.

[29] Kim, Y.J., Kim, H.C., Ko, H., Amor, E.C., Lee, J.W., and Yang, H.O., 2012, Inhibitory effects of aurentiacin from Syzygium samarangense on lipopolysaccharide-induced inflammatory response in mouse macrophages, Food Chem. Toxicol., 50 (34), 1027-1035.

[30] Wollenweber, E., Kohorst, G., Mann, K., and Bell, J.M., 1985, Leaf gland flavonoids in Comptonia peregrina and Myrica pensylvanica (Myricaceae), J. Plant Physiol., 117 (5), 423-430.

[31] Ragasa, C.Y., Franco, F.C., Raga, D.D., and Shen, C.C., 2014, Chemical constituent of Syzygium samarangense, Deer Pharma Chem., 6 (3), 256-260.

[32] Memon, A.H., Ismail, Z., Aisha, A.F.A., Al-Suede, F.S.R., Hamil, M.S.R., Hashim, S., Saeed, M.A.A., Laghari, M., and Abdul Majid, A.M.S., 2014, Isolation, characterization, crystal structure elucidation, and anticancer study of dimethyl cardamonin, isolated from Syzygium campanulatum Korth, Evidence-Based Complementary Altern. Med., 2014, 470179.

[33] Tantyani, T.A., and Taufikurohmah, T., 2020, Antibacterial and antifungal activities of silver nanoparticles against Neisseria gonorrhoeae and Candida albicans, Intl. J. Res. Granthaalayah, 8 (6), 179-187.

[34] Al Aboody, M.S., and Mickymaray, S., 2020, Antifungal efficacy and mechanisms of flavonoids, Antibiotics, 9 (2), 45.

[35] Mierziak, J., Kostyn, K., and Kulma, A., 2014, Flavonoids as important molecules of plant 
interactions with the environment, Molecules, 19 (10), 16240-16265.

[36] Oliveira, V.M., Carraro, E., Auler, M.E., and Khalil,
N.M., 2016, Quercetin and rutin as potential agents antifungal against Cryptococcus spp., Braz. J. Biol., 76 (4), 1029-1034. 